\title{
Seed germination and seedling growth of bean (Phaseolus vulgaris) as influenced by magnetized saline water
}

\section{Fateme Aghamir a, Hosseinali Bahrami a,*, Mohammad Jafar Malakouti a, Saeid Eshghi b, Foroud Sharifi c}

a Tarbiat Modares University, Faculty of Agriculture, Department of Soil Science, Iran

b Shiraz University, Faculty of Agriculture, Department of Horticultural Science, Iran

c Iran Soil Conservation and Watershed Management Research Institute, Iran

\begin{abstract}
Magnetized water is considered eco-friendly physical presowing seed germination.The aim of this study was to evaluate the effects of magnetized watertreatments on bean (Phaseolus vulgaris) germination under saline conditions $(0,25,50,75,100$ and $120 \mathrm{mM} \mathrm{NaCl})$. This experiment was performed as factorial in a complete randomized design (CRD) with three replications. The results revealed that the roots and shoots length, fresh and dry weight of shoots and roots and roots to shoots ratio, chlorophyll content index, water uptake, tissue water

\section{Article Info}

Received : 13.04 .2015

Accepted : 18.08.2015 contentwere significantly affected by magnetized water.Irrigation with magnetized water significantly increased the physiologic factors such as germination percentage and index, vigor index and salt tolerance index, compared to untreated control seeds.Mean germination time and parameters $\mathrm{T}_{1}, \mathrm{~T}_{10}, \mathrm{~T}_{25}, \mathrm{~T}_{50}$ and $\mathrm{T}_{90}$ (required time for germination of one to 90 percent of seeds) were reduced significantly in all magnetized water treated plants in comparison to control.The results also demonstrated that magnetized water was conducive to promote the growth of bean seedlings under saline conditions.
\end{abstract}

Keywords: Chlorophyll content index, physiological parameters, salinity, vigor index

(C) 2016 Federation of Eurasian Soil Science Societies. All rights reserved

\section{Introduction}

Magnetic and electromagnetic treatments arebeingused in agriculture, as a noninvasive technique, to improve the germination of seeds and increase crops and yields (Martinez et al., 2009). A safe method for enhancing seed germination includes the reasonable use of chemical additives and substitution by appropriate physical treatment. In recent years, there are growing concerns of eco-friendly physical presowing seed treatments by newly developed methods such as magnetic field (MF) (Jamil et al., 2012). The effects of different MFs varies depending on the age during exposure as well as the induction of the field (magnetic field strength), period of exposure and environmental conditions such as temperature, humidity, etc. (Pang and Dang, 2008).

In the beginning of 1980s, Fujio Shimazaki, a Japanese researcher, reveal that some physical andchemical properties of water changed when it pass through MF; hecalled the passed water through MF, "magnetized water" (MW) which lead to special functions (Cai et al., 2009); however,many researchers reported that MW could promote germination and early growth (Qiuet al., 2011). Hilal and Hilal (2000) showed that comparision between MF and MW in different treatment seeds. Magneticfieldtreatments had doubled germination compared to MW ones on pepper seeds; however, tomato and cucumber seeds had responded more to MW rather than MF. Soaking seeds is a crucial factor to enable MF effects because of the water's role

\footnotetext{
${ }^{*}$ Corresponding author.

Tarbiat Modares University, Faculty of Agriculture, Department of Soil Science, Iran

Tel.: +9844580500
}

E-mail address: bahramih@modares.ac.ir

e-ISSN: 2147-4249

DOI: http://dx.doi.org/10.18393/ejss.2016.1.039-046 
as MF mediator.Both MW and MF treatments have succeeded to given the highest germination percentage for cucumber cousing 86\% increase over control (Hilal and Hilal, 2000). Magnetization of both seeds and water has come to be the most effective treatment in seed germination as compared with control (Selim, 2008). Function of MW depends on induction, types (dynamicorstatic), length, andconfigurations of homogeneous and heterogeneous of MF, numbers of repetitions of the process (flow revalations), water flowpressure, material of pipeand composition of dissolved salts (Vashisth and Nagarajan, 2010). Dynamic and static MW treatment improved rice seed germination and significant differences compared to control were only obtained for the dynamic method (Carbonell et al., 2000).

Extensive research has revealed that the effects of MW depend on a wide range of factors including specialenvironmental conditions such as temperature, humidity, and salinity (Gutzeit, 2001). Despite, MW improved crop resistance in the alkali and salt conditions (Dandan and Yan, 2013) and the mechanism of its effects highly depending on the concentration and composition of the dissolved salts (Ibrahim Mohamed and Mohsen Ebead, 2013), there is a relatively little scientific literature on germination mechanism of MW in saline condition. The present study was conducted to analyze the effects of MW, with six different salt concentrations, on bean germination and seedling growth parameters.

\section{Material and Methods}

The magnetized water was produced byan electromagnetic field generator (Water Clear Environment Technologies Company-SB 150) with signal cable is changed any where from 2000 to 24000 times a second produces an oscillating and complex modulating frequency wave from the produces an inaudible sonic impluse magnetic field strength (0.05-0.5mT).

Seed germination tests were conducted as a factorial experiment arranged in a complete randomized design (CRD) with three replications. Seeds were sterilized by sodium hypochlorite and distilled water, placed in petri dishes on a wet filter paper. Each treatment category (100 seeds) was irrigated with $20 \mathrm{ml}$ of MW and non MW $(0,25,50,75,100$ and $120 \mathrm{mM} \mathrm{NaCl})$. Seeds germinated in an incubator at $25^{\circ} \mathrm{C}$ and a relative humidity of 50\% (ISTA, 2004). Water uptake percentage (WUP) was recorded for 15 hours calculated by the formula 1 according to Mujeeb-ur-Rahman et al. (2008).

$$
W U P=\frac{W_{2}-W_{1}}{W_{1}} \times 100
$$

Where $\mathrm{W}_{1}=$ initial weight of seed, and $\mathrm{W}_{2}=$ weight of seed after absorbing water in a particular time. The pot experiment was conducted with the aforementioned treatments "MW and non MWin a cultivated media box filled with peatmoss and perlite (1:1). For each treatment category, 100 seeds was sown at the depth of $2 \mathrm{~cm}$ with three replications. The boxes were placed in green house at $25^{\circ} \mathrm{C}$. After 2 weeks, plants harvested and then the growth paramerets, including the roots and shoots length (RL and SL), fresh and dry weight of shoots and roots (FWR, DWR, FWS and DWS) and roots to shoots ratio (R/S) were measured with scale $0.001 \mathrm{~g}$.

Dry weights were determined after samples were oven-dried at $70^{\circ} \mathrm{C}$ for $48 \mathrm{~h}$. Chlorophyll content index (CCI) of fresh seedling leaves was determined using a portable chlorophyll content meter (CCM-200, OPTISCIENCES, Tyngsboro, MA,USA) based on absorbance measurements at 660 and $940 \mathrm{~nm}$ (Markwell et al., 1995).

The tissue water content (TWC) was calculated based on equation 2 (Black and Pritchard, 2002).

$$
T W C=\frac{\text { Freshweight }- \text { Dry weight }}{\text { Freshweight }} \times 100
$$

The physiological factors consisted of germination percentage (GP), germination index (GI), vigor index (VI), salt tolerance index (STI), required time for germination of one to 90 percent of seeds (parameters $\mathrm{T}_{1}, \mathrm{~T}_{10}$, $\mathrm{T}_{25}, \mathrm{~T}_{50}$, and $\mathrm{T}_{90}$ ) and mean germination time (MGT) were calculated based on equations 3 and 4 .

$$
\begin{aligned}
& G P=\frac{n}{N} \times 100 \\
& G I=\sum \frac{\left(n_{i} \times T_{i}\right)}{N}
\end{aligned}
$$


Where $\mathrm{n}$ represents the number of newly germinating seeds, and $\mathrm{N}$ total number of seeds; $\mathrm{n}_{\mathrm{i}}$ is number of seeds germinated at day $\mathrm{T}_{i}$ and $\mathrm{T}_{\mathrm{i}}$ is number of days after starting the test (Panwar and Bhardwaj, 2005). Seedling vigor index was calculated based on Abdul-Baki and Anderson (1973).

$$
\begin{aligned}
& V I(I)=G P \% \times \text { Seedling Lenght }(\text { Root }+ \text { Shoot }) \\
& V I(I I)=G P \% \times \text { Seedling Dry Weight }(\text { Root }+ \text { Shoot }) \\
& S T I=\frac{\text { Seedling Dry Weight }(\text { Root }+ \text { Shoot }) \text { at } S_{x}}{\text { Seedling Dry Weight }(\text { Root }+ \text { Shoot }) a t S_{0}}
\end{aligned}
$$

Where, $S_{0}$ represents control and $S_{x}$ a given salt concentration.The rate of germination was assessed by determining the required time for germination of $1,10,25,50,75$ and $90 \%$ of seeds $\left(\mathrm{T}_{1}, \mathrm{~T}_{10}, \mathrm{~T}_{25}, \mathrm{~T}_{50}, \mathrm{~T}_{90}\right)$ (Carbonell et al., 2008) and the mean time germinating (MTG) calculated according to the equation 8 (Panwar and Bhardwaj, 2005).

$M T G=\sum\left(\frac{n_{i}}{T_{i}} \times 100\right)$

Where, $T_{i}$ is the number of days after starting the experiment and $n_{i}$ represent the total number of germinated seeds on the $i^{\text {th }}$ day.

\section{Statistical Analysis}

ANOVA test was used for analyzing the data by using Minitab software at $5 \%$ probality level.

\section{Results and Discussion}

Analysis of variance of bean seed germination parameters are presented in Tables 1 and 2, and Figures 1 and 2.

Table 1. Analysis of variance for growth and developmental parameters of corn under different salinity levels and magnetized water regimes; RL and SL (roots and shoots length, FWR, DWR, FWS, DWS (fresh and dry weight of shoots and roots), R/S (roots to shoots ratio), TWC (tissue water content), WUP (water uptake percentage, WT (water treatment: magnetized and non-magnetized) and EC (electrical conductivity).

\begin{tabular}{lccccccc}
\hline Source & $\mathrm{df}$ & $\mathrm{RL}$ & $\mathrm{SL}$ & $\mathrm{FWR}$ & $\mathrm{DWR}$ & $\mathrm{FWS}$ & $\mathrm{DWS}$ \\
\hline WT & 1 & $273.903^{* *}$ & $110.600^{* *}$ & $8.107^{* *}$ & $0.088^{* *}$ & $6.003^{* *}$ & $0.046^{* *}$ \\
EC & 5 & $102.170^{* *}$ & $42.357^{* *}$ & $0.831^{* *}$ & $0.008^{* *}$ & $2.276^{* *}$ & $0.015^{* *}$ \\
WT*EC & 5 & $3.294^{* *}$ & $6.736^{* *}$ & $0.259^{* *}$ & $0.003^{* *}$ & $0.374^{* *}$ & $0.002^{* *}$ \\
\hline Source & $\mathrm{df}$ & $\mathrm{FWP}$ & $\mathrm{DWP}$ & $\mathrm{R}_{\mathrm{f}} / \mathrm{S}_{\mathrm{f}}$ & $\mathrm{R}_{\mathrm{d}} / \mathrm{S}_{\mathrm{d}}$ & $\mathrm{TWC}$ & WUP \\
\hline WT & 1 & $28.062^{* *}$ & $0.260^{* *}$ & $0.968^{* *}$ & $0.773^{* *}$ & $1189.53^{* *}$ & $785.401^{* *}$ \\
EC & 5 & $5.850^{* *}$ & $0.045^{* *}$ & $0.006^{*}$ & $0.012^{*}$ & $431.22^{* *}$ & $252.516^{* *}$ \\
WT*E & 5 & $1.029^{* *}$ & $0.008^{* *}$ & $0.173^{* *}$ & $0.038^{* *}$ & $12.12^{* *}$ & $10.528^{* *}$ \\
\hline
\end{tabular}

** and *: significant at $P=0.01$, and $P=0.05$, respectively; $d f$ : degree of freedom.

Table 2. Analysis of variance for corn physiological parameters as effected by magnetized water regimes and salinity; CCI (chlorophyll content index), GP (germination percentage), GI (germination index), VI (vigor index), STI (salt tolerance index), MTG (mean time generation), $\mathrm{T}_{1}, \mathrm{~T}_{10}, \mathrm{~T}_{25}, \mathrm{~T}_{50}, \mathrm{~T}_{75}, \mathrm{~T}_{90}$ (required time for germination of seeds from one to $90 \%$ ), WT (water treatment: magnetized and non-magnetized) and EC (electrical conductivity).

\begin{tabular}{lccccccc}
\hline Source & df & CCI & GP & GI & VI(I) & VI(II) & STI \\
\hline WT & 1 & $312.111^{* *}$ & $1133.44^{* *}$ & $6.996^{* *}$ & $4489172^{* *}$ & $1470.340^{* *}$ & $1.046^{* *}$ \\
EC & 5 & $97.019^{* *}$ & $1178.24^{* *}$ & $8.004^{* *}$ & $2010007^{* *}$ & $416.450^{* *}$ & $0.332^{* *}$ \\
WT*EC & 5 & $4.208^{* *}$ & $27.78^{* *}$ & $0.402^{* *}$ & $144379^{* *}$ & $57.490^{* *}$ & $0.056^{* *}$ \\
\hline Source & df & MTG & T1 & T10 & T25 & T50 & T90-T10 \\
\hline WT & 1 & $18.431^{* *}$ & $20.026^{* *}$ & $6.003^{* *}$ & $20.25^{* *}$ & $8.028^{* *}$ & $4.694^{* *}$ \\
EC & 5 & $1.454^{* *}$ & $1.447^{* *}$ & $2.306^{* *}$ & $2.583^{* *}$ & $0.628^{\text {ns }}$ & $10.094^{* *}$ \\
WT*E & 5 & $0.347^{* *}$ & $0.187^{* *}$ & $0.415^{*}$ & $1.117^{* *}$ & $0.494^{\text {ns }}$ & $0.228^{\text {ns }}$ \\
\hline
\end{tabular}

**, * and, ns: significant at $P=0.01, P=0.05$ and no significant, respectively; $d f$ : degree of freedom. 


\section{Growth parameters}

Analysis of variance of the growth parameters including roots and shoots lenght, fresh and dry weight of roots and shoots, roots to shoots ratio, tissue water content and water uptake percentage exposed to magnetized water are shown in Table 1 and Figure 1.
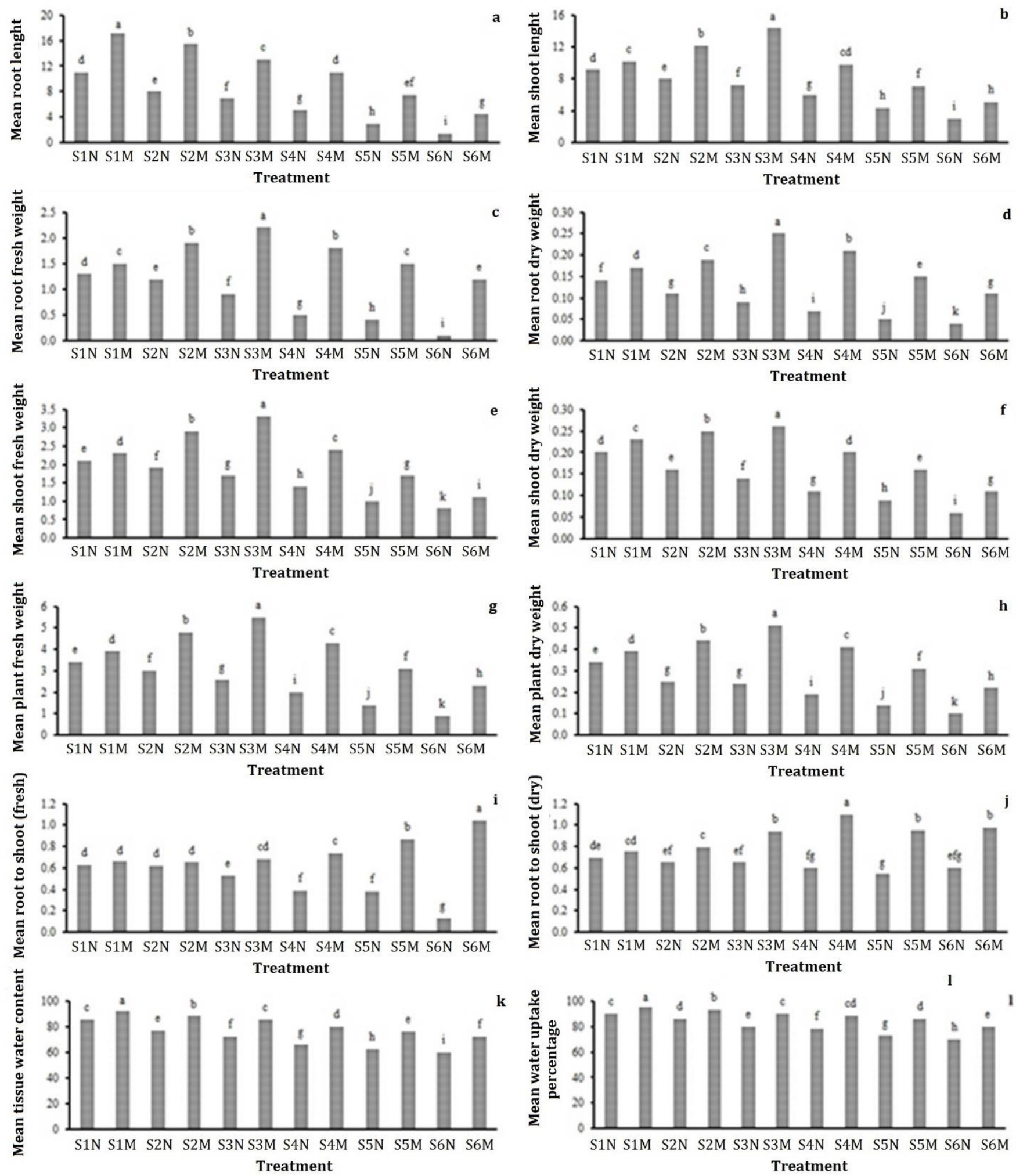

Figure 1. Effects of magnetized saline water on growth parameters of bean germination

(M: Magnetized and N : Non magnetized water, S: Salinity) 


\section{Roots and shoots length}

Root length provides an important clue to the response of plants to salinity stress. Analysis of variance in table 1 showed that shoot and root length of the magnetized saline water treated seedlings were higher than seedlings treated by saline water. Salt stress inhibited the growth of root more than shoot in all treatments. Root and shoot length decreased by increasing $\mathrm{NaCl}$ concentration. A marked reduction in RL and SL of nonMW treatments was observed following salt stress (Figure 1a,b). The result showed that RL and SL of the magnetized saline water treatments siginificantly were higher than control by 69 and 40\%, respectively (Table1). Mahmood and Usman (2014) reported similar results on maize seed germination, as in their experiment, magnetized saline water significantly increased SL up to $10.24 \%$ compared to saline water.

\section{Roots and shoots dry and fresh weight}

Salt stress decreased FWR, DWR, FWS and DWS in non-MW treatments (Figure 1c,d,e,f). Reduction in weight can be due to proportional increase in $\mathrm{Na}^{+}$concentration which disturbs ionic and osmotic balances; however, dry weights were not much affected compared to the fresh weights. A significant increase in FWR, DWR, FWS and DWSoccured in the magnetized saline water treated seedlings as compared to the control (Table 1). There were significant differences between treatments for roots to shoots ratio (R/S) (Table 1). As $\mathrm{NaCl}$ concentration increased, it unequally affected roots and shoots weight. The result of R/S represented that salt stress inhibited the growth of roots more than shoots in all non-MW treatments (Figure 1i,j). Other authors have reported similar findings (Jamil et al., 2006). As $\mathrm{NaCl}$ levels increased the ratio of roots to shoots dry weight remarkably decreased. Reduction of dry weights relatively depended on shoot or root lengths. Along with increase in $\mathrm{NaCl}$ concentration in magnetized saline water treatments, the $\mathrm{R} / \mathrm{S}$ gradually increased (up to $75 \mathrm{mM} \mathrm{NaCl}$ ) (Figure $1 \mathrm{i}$, j), then decreased; however, it was significantly higher than nonMW treatments.

\section{Tissue water content (TWC)}

Magnetized water increased TWC significantly in compairison with non-MW treatments (Table 1 and Figure $1 \mathrm{k}$ ). Along with increase in the salinity intensity, Kang and Saltvett (2002) reported that the osmotic pressure leads to a reduction of water absorbance and inhibition cell division and differentiation;, which adversely affects metabolic and physiological processes, and this causes more delay in initiation of germination followed by prolonged seed germination duration, and ultimately reduces germination parameter and seedling growth. It seems that MW decreases injurious effects of salinity by increaseing water absorption.

\section{Water uptake percentage}

As $\mathrm{NaCl}$ concentration increased (up to $120 \mathrm{Mm}$ ) WUP decreased in all treatments (Figure 1l). Increase in salinity level decreased germination parameters and seedling growth which are directly related to external osmotic potential preventing water uptake. Bean seeds exposure to MW increased WUP significantly compaired to non-MW treatments (Table 1). The result are in agreement with other researchers, which indicates that MW treated seeds absorbed more water and absorbed it faster than untreated seeds (Kaya et al., 2006); moreover, results of this study are in agreement with findings which lettuce seeds exposure to static MF causes increase in water uptake rate (Reina et al., 2001). MF changes both osmotic pressure and ionic concentrations in the membrane angles, which regulates the water absorbance (Azharonok et al., 2009).

\section{Physiological parameters}

Analysis of variance of physiological factors included chlorophyll content index, germination percentage, germination index, vigor index, salt tolerance index, mean germination time and required time for germination of seeds from one to 90\%, whichare shown in Table 2 and Figure 2.

\section{Chlorophyll content index (CCI)}

As $\mathrm{NaCl}$ levels increased, the CCI decreased remarkably (Figure 2a) due to enzymatic chlorophyll degradation (Xu et al., 2000). Magnetized saline water significantly increases CCI as compared to non-MW (Table 2). This result was in agreement with previous works as it has been reported that MW increased chlorophyll content of wheat, flax, and lentil (Qados and Hozayn, 2010) byincreasing the activity of the chlorophyll degrading enzyme: Chlorophyllase (Jamil et al., 2007). 

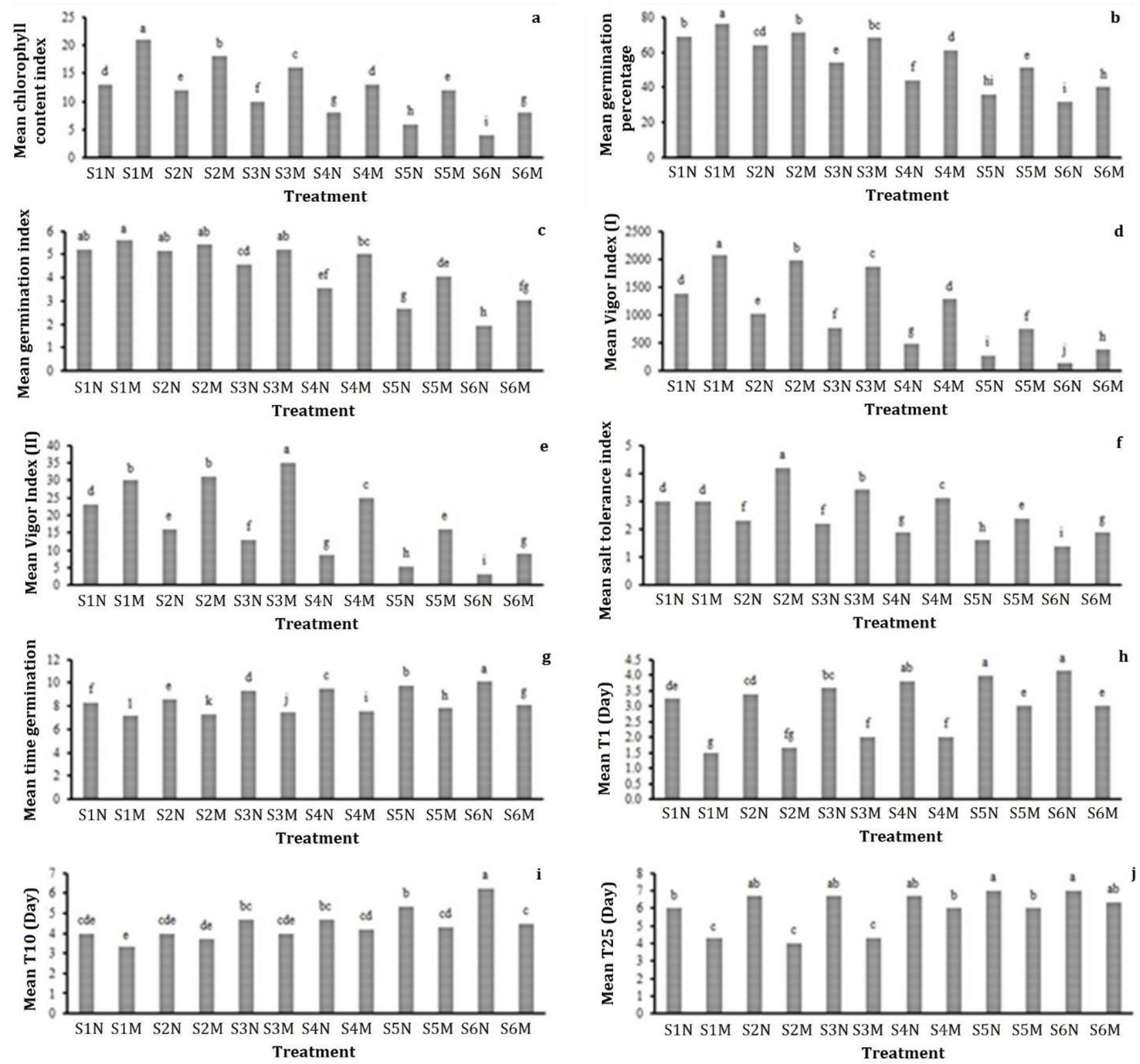

Figure 2. The bean physiological parameters as affected by magnetized water and salinity

(M: Magnetized and N : Non magnetized water, S: Salinity)

\section{Germination Percentage(GP)}

The analysis of variance showed magnetized saline water had significant effect on GP compared with non magnetized saline water (Table 2). Previous studies have shown that static and dynamic MW improved GP of rice seeds (Carbonell et al., 2000); moreover, it increased GP of pepper 35.8\% over control (Ahamed et al., 2013). Increasing the salinity level increases the time required for germination. Some studies have reported that increasing the salt concentration delays the tomato seeds germination (Mohamed and Ebead, 2013).

\section{Germination Index (GI)}

Germination test showed magnetized saline water had a significant effect on GI in comparison to control seeds (Table 2). The result confirmed the study of Mahmood and Usman (2014), who indicated improvement of GI from 10.20 to 11.85 in seedlings treated with saline magnetized water in comparison with the control. The enhanced speed of seedgermination does suggest that magnetized water hasacquired some structural changes; perhaps promotingwater flow and bioactive molecules availability. 


\section{Vigor index (VI)}

Vigor Index (I) values based on seedling length and GP showed a trend similar to seedling shoots and roots length in non-MW treated seedlings. In magnetized saline water treatments, as $\mathrm{NaCl}$ levels increased, the VI(I) gradually decreased (Figure 2d); however, it was significantly higher than non-MW treatments. MW improved VI(II) values based on seedling dry weight and GP (Table 2). Along with increase in $\mathrm{NaCl}$ levels, VI(II) increased (up to $50 \mathrm{Mm} \mathrm{NaCl}$ ) in all magnetized saline water treatments, then decreasded (Figures 1 and 2); however, it was significantly higher than non-MW treatments (Table 2).

\section{Salt tolerance index (STI)}

At different levels of $\mathrm{NaCl}$, STI was significantly different and decreased with increasing in salinity intensity (Figure 2f). The magnetized saline water had significant effect on increasing STI in comparison to control seeds (Table 2). This results were in agreement with the findings of Dandan and Yan (2013) who indicated that applications of magnetically saline water increased STI of wheat and guinea grass.

\section{Mean time germination (MTG)}

Magnetized saline water treatment had significantly lower MTG than the control treatments (Table 2 and Figure 2g). Results are in agreement with the germination data obtained by Mahmood and Usman (2014) that magnetized saline water reduced MTG from 9.15 to 8.73 and germination completed two to three days earlier than control. Time parameters $\left(\mathrm{T}_{1}, \mathrm{~T}_{10}, \mathrm{~T}_{25}, \mathrm{~T}_{50}\right.$, and $\left.\mathrm{T}_{90}\right)$ in magnetized saline water treatments significantly were lower than control (Table2), indicated less time required for seed germination, and germination speed is higher. Parameters $\mathrm{T}_{1}$ and $\mathrm{T}_{10}$ are related to the beginning of germination, this study represents a progress in germination and a reduction in the induction phase in most of the magnetized saline water treatments applied.

\section{Conclusion}

Results of the current study revealed the positive and significant impacts of magnetic water on physiologic factors, and growth and development parameters of bean (Phaseolus vulgaris) comparison with the control. The stimulatory effect of magnetic water on the growth in this research may be due to the increase in roots and shoots growth. Therefore, as a simple and safe method, irrigation with magnetic water can be used to improve plant growth and water use efficiency. The results also demonstrated that magnetized water increased the bean seedling tolerance under salinity conditions. Generally, using magnetic water treatment could be a promising technique for agricultural improvements but extensive research is required on different crops.

\section{References}

Abdul-Baki, A.A., Anderson, J.D., 1973. Vigor determination in soybean by multiple criteria. Crop Science 13: 630-633.

Ahamed, M.E.M., Elzaawely, A.A., Bayoumi, Y.A., 2013. Effect of magnetic field on seed germination, growth and yield of sweet pepper (Capsicum annuum L.). Asian Journal of Crop Science 5: 286-294

Azharonok, V.V., Goncharik, S.V., Filatova, I.I., Shik, A.S., Antonyuk, A.S., 2009. The effect of the high frequency electromagnetic treatment of the sowing material for legumes on their sowing quality and productivity. Surface Engineering and Applied Electrochemistry 45: 317-327.

Black, M., Pritchard, H., 2002. Desiccation and survival in plants drying without dying. New York: CABI publishing.

Cai, R., Yang, H., He, J., Zhu, W., 2009. The effects of magnetic fields on water molecular hydrogen bonds. Journal of Molecular Structure 938: 15-19.

Carbonell, M.V., Martinez, E., Amaya, J.M., 2000. Stimulation of germination in rice (Oriza sativa L.) by a static magnetic field. Electromagnetic Biology and Medicine 19: 121-128.

Carbonell, M.V., Martinez, E., Florez, M., Maqueda, R., Lopez-Pintor, A., Amaya, J.M., 2008. Magnetic field treatments improve germination and seedling growth in Festuca arundinacea Schreb and Loliumperenne L. Seed Science and Technology 36: 31-37.

Dandan, L., Yan, S., 2013. Effects of magnetized saline on growth and development of winter wheat seedlings. Advance Journal of Food Science and Technology 5(12): 1596-1599.

Gutzeit, H.O., 2001. Biological effects of ELF-EMF enhanced stress response: new insights and new questions. Electroand Magnetobiology 20(1): 15-26.

Hilal, M.H., Hilal, M.M., 2000. Application of magnetic technologies in desert agriculture: I-Seed germination and seedling emergence of some crops in a saline calcareous soil. Egyptian Journal of Soil Science 40(3): 413-423. 
Ibrahim Mohamed, A., Mohsen Ebead, B., 2013. Effect of irrigation with magnetically treated water on faba bean growth and composition. International Journal of Agricultural Policy and Research 1(2): 24-40.

ISTA., 2004. International Rules for Seed Testing. International Seed Testing Association. Zurich.

Jamil, M., Lee, D.B., Jung, K.Y., Ashraf, M., Lee, S.C., Rha, E.S., 2006. Effect of salt (NaCl) stress on germination and early seedling growth of four vegetables. Journal of Central European Agriculture 7(2): 273-282.

Jamil, M., Rehman, S., Lee, K.J., Kim, J.M., Kim, H.S., Rha, E.S., 2007. Salinity reduced growth PS II photochemistry and chlorophyll content in radish. Scientia Agricola 64: 1-10.

Jamil, Y., Haq, Z., Iqbal, M., Jamil, T., Amin, N., 2012. Enhancement in growth and yield of mushroom (Pleurotus ostreatus) using magnetic field treatment. International Agrophysics 26 (4): 375-380.

Kang, H.M., Saltveit, M.E., 2002. Chilling tolerance of maize, cucumber and rice seedlings leaves and roots are differently affected by salicylic acid. Physiologia Plantarum 115: 571-576.

Kaya, M.D., Okcu, G., Atak, M., 2006. Seed treatments to overcome salt and drought stress during germination in sunflower (Helianthus annuus L.). European Journal of Agronomy 24: 291-295.

Mahmood, S., Usman, M., 2014. Consequences of magnetized water application on maize seed emergence in sand culture. Journal of Agricultural Science and Technology 16: 47-55.

Markwell, J., Osterman, J.C., Mitchell, J.L., 1995. Calibration of the Minolta SPAD-502 leaf chlorophyll meter. Photosynthesis Research 46: 467-472.

Martinez, E., Carbonell, M.V., Flórez, M., Amaya, J.M., Maqueda, R., 2009. Germination of tomato seeds (Lycopersicon esculentumL.) under magnetic field. International Agrophysics 23: 45-49.

Mohamed, A.I., Ebead, B.M., 2013. Effect of magnetic treated irrigation water on salt removal from a sandy soil and on the availability of certain nutrients. International Journal of Engineering2(2): 2305-8269.

Mujeeb-ur-Rahman, U.A.S., Mohammad, Z., Shereen, G., 2008. Effects of NaCl Salinity on Wheat (Triticum aestivum L.) Cultivars. World Journal of Agricultural Sciences 4(3): 398-403.

Pang, X.F., Deng, B., 2008. The changes of macroscopic features and microscopic structures of water under influence of magnetic field. Physica B: Condensed Matter 403: 3571-3577.

Panwar, P., Bhardwaj, S.D., 2005. Handbook of Practical Forestry. Agrobios, India.191p.

Qados, A., Hozayn, M., 2010. Magnetic water technology, a novel tool to increase growth, yield, and chemical constituents of Lentil (Lens esculenta) under greenhouse condition. American-Eurasian Journal of Agricultural and Environmental Sciences 7(4): 457-462.

Qiu, N.W., Tan, T.H., Dai, H., Shen, X., Han, R., Lin, Y., Ma, Z.Q., 2011. Biological effects of magnetized water on seed germination, seedling growth and physiological characteristics of wheat. Plant Physiology Journal 47(8): 803-810.

Reina, F.G., Pascual, L.A., Fundora, I.A., 2001. Influence of a stationary magnetic field on water relations in lettuce seeds. Part II: Experimental Results. Bioelectromagnetics 22: 596-602.

Selim, M.M., 2008. Application of magnetic technologies in correcting underground brackish water for irrigation in the arid and semi-arid ecosystem. The $3^{\text {rd }}$ International Conference on Water Resources and Arid Environments.

Vashisth, A., Nagarajan, S., 2010. Effect on germination and early growth characteristics in sunflower (Helianthus annuus) seeds exposed to static magnetic field. Journal of Plant Physiology 167: 149-156.

Xu, X.M., Ye, H.C., Li, G.F., 2000. Progress in research of plant tolerance to saline stress. Chinese Journal of Applied \& Environmental Biology 6(4): 379-387. 